\title{
$\checkmark$ Research Square \\ Observational constraints reduce estimates of the global mean climate relevance of black carbon
}

\section{Gunnar Myhre ( $\nabla$ gunnar.myhre@cicero.oslo.no)}

CICERO Center for International Climate Research - Oslo, 0318 Oslo https://orcid.org/0000-0002-4309476X

\section{Bjørn Samset}

CICERO Center for International Climate and Environmental Research in Oslo https://orcid.org/00000001-8013-1833

\section{Camilla Weum Stjern}

Center for International Climate and Environmental Research in Oslo

\section{Øivind Hodnebrog}

CICERO Center for International Climate Research https://orcid.org/0000-0001-5233-8992

\section{Ryan Kramer}

NASA

\section{Christopher Smith}

University of Leeds https://orcid.org/0000-0003-0599-4633

\section{Piers Forster}

University of Leeds https://orcid.org/0000-0002-6078-0171

\section{Timothy Andrews}

Met Office https://orcid.org/0000-0002-8248-8753

\section{Olivier Boucher}

Institut Pierre-Simon Laplace, Sorbonne Université/CNRS

\section{G Faluvegi}

Columbia University, New York https://orcid.org/0000-0001-9011-3663

\section{Drew Shindell}

Duke University https://orcid.org/0000-0003-1552-4715

\section{Alf Kirkevåg}

Norwegian Meteorological Institute

\section{Trond Iversen}

Norwegian Meteorological Institute

\section{Dirk Olivie}

Norwegian Meteorological Institute

\section{Philip Stier}

University of Oxford https://orcid.org/0000-0002-1191-0128

\section{Duncan Watson-Parris}


University of Oxford https://orcid.org/0000-0002-5312-4950

\section{Article}

Keywords: black carbon (BC), climate effects, global warming

Posted Date: July 29th, 2021

DOI: https://doi.org/10.21203/rs.3.rs-691895/v1

License: (c) (i) This work is licensed under a Creative Commons Attribution 4.0 International License. Read Full License 


\section{Observational constraints reduce}

2 estimates of the global mean climate

s relevance of black carbon

4

5

6

Gunnar Myhre $^{1 *}$, Bjørn Samset ${ }^{1}$, Camilla Weum Stjern ${ }^{1}$, Øivind Hodnebrog ${ }^{1}$, Ryan Kramer ${ }^{2}$, Chris Smith $^{3.4}$, Timothy Andrews ${ }^{5}$, Olivier Boucher ${ }^{6}$, Greg Faluvegi ${ }^{7,8}$, Piers M. Forster ${ }^{3}$, Trond Iversen ${ }^{9}$, Alf Kirkevåg ${ }^{9}$, Dirk Olivié ${ }^{9}$, Drew Shindell ${ }^{10}$, Philip Stier ${ }^{11}$, Duncan WatsonParris $^{11}$

${ }^{1}$ CICERO Center for International Climate Research, Oslo, Norway

${ }^{2}$ NASA Goddard Space Flight Center, Earth Sciences Division, Greenbelt, MD, USA

${ }^{3}$ School of Earth and Environment, University of Leeds, Leeds, UK

${ }^{4}$ International Institute for Applied Systems Analysis (IIASA), Laxenburg, Austria

${ }^{5}$ Met Office Hadley Centre, Exeter, UK,

${ }^{6}$ Institut Pierre-Simon Laplace, Sorbonne Université/CNRS, Paris, France

${ }^{7}$ Center for Climate System Research, Columbia University, New York, NY, USA

${ }^{8}$ NASA Goddard Institute for Space Studies, New York, NY, USA

${ }^{9}$ Norwegian Meteorological Institute, Oslo, Norway

${ }^{10}$ Nicholas School of the Environment, Duke University, Durham, NC, USA

${ }^{11}$ Atmospheric, Oceanic and Planetary Physics, Department of Physics, University of Oxford, Oxford, UK

*Corresponding author: gunnar.myhre@ cicero.oslo.no

How emissions of black carbon $(B C)$ aerosols affect the climate is still uncertain, due to incomplete knowledge of its sources, optical properties and atmospheric processes such as transport, removal and impact on clouds. Here we constrain simulations from four climate models with observations of atmospheric $B C$ concentrations and absorption efficiency, and the most recent emission inventories, to show that the current global mean surface temperature change from anthropogenic $B C$ emissions is likely to be weak at $+0.03 \pm 0.02 \mathrm{~K}$. Atmospheric rapid adjustment processes are found to reduce the top of atmosphere radiative imbalance relative to instantaneous radiative forcing (direct aerosol effect) by almost $50 \%$ as a multimodel mean. Furthermore, constraining the models to reproduce observational estimates of the atmospheric vertical profile reduces $B C$ effective radiative forcing to $0.08 \mathrm{~W} \mathrm{~m}^{-2}$, a value more than $50 \%$ lower than in unconstrained simulations. Our results imply a need to revisit commonly used climate metrics such as the global warming potential of BC. This value (for a 100-year time horizon) reduces from 680 when neglecting rapid adjustments and using an unconstrained BC profile to our best estimate of $160 \pm 120$. 
Atmospheric black carbon (BC) aerosols, emitted from incomplete combustion of fossil fuel, biofuel and biomass burning, can absorb incoming solar radiation ${ }^{1-3}$, and is generally thought to exert a positive net radiative forcing due to the direct interaction with sunlight. BC shortwave absorption efficiency is highly dependent on the underlying albedo, and is particularly strong over bright surfaces and above clouds ${ }^{1}$. Estimates of the direct aerosol effect of $B C$ differ for a variety of reasons related to emissions, absorptive properties, atmospheric abundance, interpretation of observations, and host climate models ${ }^{2,4}$. The atmospheric warming from BC alters clouds ${ }^{5,6}$, but whether this enhances or counteracts the direct influence on the radiation budget differs between various studies ${ }^{7,8}$. The sign of the $B C$ influence on clouds is mainly dependent on whether BC is located above or below clouds ${ }^{9-11}$, while the strength of the impact depends on atmospheric conditions and cloud properties ${ }^{11}$. Available estimates of the $B C$ induced cloud changes are mainly from models with spatial resolutions ranging from hundreds of kilometers (global scale models) to tens of meters (large eddy simulations) ${ }^{7,10,12}$, and are partly based on satellite retrievals ${ }^{13,14}$. While most model studies assessing the temperature response from $B C$ have been single-model simulations, two multi-model studies exist ${ }^{15,16}$. The direct absorption occurs almost entirely in the solar spectrum but the consequences of the resulting atmospheric heating (e.g., in form of cloud changes) also influences the thermal infrared radiation ${ }^{17}$. BC is to a large extent co-emitted with scattering aerosols, where the global overall aerosol cooling effect is stronger in magnitude than the heating from $B C^{8,18}$.

Underestimation of absorption by BC in global models compared to observations has been extensively discussed ${ }^{2}$. The cause is associated with uncertainties in measurements ${ }^{19}$ and in model simulations of other aerosol types contributing to absorption, such as dust and absorbing organic aerosols. Nevertheless, a crucial factor for the BC absorption is the mass absorption coefficient, which is likely underestimated by about $25-50 \%$ in global climate models ${ }^{15}$ compared to regional measurements ${ }^{20}$. Furthermore, emissions of $\mathrm{BC}$ vary among available datasets ${ }^{21}$ and a recent data set indicates higher emissions ${ }^{22}$ than used in previous multi-model exercises ${ }^{8}$. Recent years, however, have seen a reduction of the $\mathrm{BC}$ emission globally ${ }^{23}$. Observations show that the concentration of BC in state-of-the-art global models is smaller in the middle and upper troposphere than in the previous generation of global aerosol models ${ }^{24-26}$. It has also been shown that not accounting for the representativeness error of observed BC concentrations or optical depths in constrained simulations could result in an important positive bias in the forcing estimate ${ }^{27}$. Overall, recent observational constraints strongly indicate that the previous generation of global models on one hand underestimate the climate effect of $B C$ due to low mass absorption coefficient values and emissions inventories, and on the other hand overestimate it by simulating too high $\mathrm{BC}$ concentrations in the upper troposphere ${ }^{28}$.

Effective radiative forcing (ERF), the top-of-atmosphere radiative perturbation due to the instantaneous radiative perturbation (IRF) after subsequent rapid adjustments (short-term atmospheric changes which are independent of surface temperature change) has been 
evaluated to be the most appropriate way to compare various climate drivers in terms of their surface temperature change ${ }^{8,29,30}$. BC IRF is a measure of the direct aerosol effect. See Fig $1 \mathrm{a}$ for an illustration of IRF, rapid adjustment, ERF and surface temperature change. A radiative imbalance at the top of the atmosphere, quantified by the ERF, causes the climate system to seek a new balance by increasing the global surface temperature, modified by climate feedbacks. A positive value for ERF implies a net gain of energy throughout the climate system. The full equilibrium climate response to an ERF is the difference between two equilibria with and without the imposed ERF.

The importance of rapid adjustment for the total influence on the atmospheric energy budget varies strongly among climate drivers, being highly important for absorbing components such as BC ${ }^{31-33}$. Smith, et al. ${ }^{31}$ showed rapid adjustments to be strongly negative for BC, with cloud changes as one of the main contributors. In this study we provide results from four climate models with $\mathrm{BC}$ responses typical for the previous generation of global models. Several of these are models already thoroughly analyzed in previous studies ${ }^{15,31,34}$. We then compare these results to new simulations where the vertical profile of $B C$ has been constrained by observations in the upper troposphere (see Methods). Additionally, we constrain the models by observations of the mass absorption coefficient, and by using the most updated BC emission data (see Methods). The scaling of the results by emissions and mass absorption coefficient are applied since the original climate model simulations were performed without the most recent progress in improved scientific knowledge of BC. Supplementary Table 1 shows a range of measurement of mass absorption coefficient. The representative observed value of $10 \mathrm{~m}^{2} \mathrm{~g}^{-1}$ is higher than the multi-model mean of $7.3 \mathrm{~m}^{2} \mathrm{~g}^{-1}$. The main focus in this study is on the radiative impact of $B C$, and on processes leading to ERF and surface temperature changes due to $\mathrm{BC}$. ERF is calculated from prescribed sea surface temperature simulations and surface temperature changes from fully coupled atmosphere-ocean simulations (see Methods).

The models and the experiment simulations are described in Methods. Three of the models employ imported atmospheric $\mathrm{BC}$ concentrations calculated elsewhere (concentration-driven simulations) whilst the fourth calculates $B C$ from emissions (emission-driven simulations). In the previously analyzed multi-model $B C$ experiment within Precipitation Driver Response Model Intercomparison Project (PDRMIP), four of the models were emission-driven out of nine models ${ }^{15}$. Two of the emissions-driven models had larger $\mathrm{BC}$ change and two of the models had weaker $\mathrm{BC}$ change. Altogether the model means of emission-driven and concentration driven models gave similar global and annual mean ERF and surface temperature change (see further discussion in the Supplementary).

Figure 1 shows IRF, rapid adjustment, ERF and surface temperature change for experiments with unconstrained $B C$ ( $B C$ STD) and vertically constrained $B C$ ( $B C V C)$ by observations. All numbers are scaled to current emissions from Community Emission Data Set (CEDS v2021) ${ }^{23}$ and to constraints from observations of the mass absorption coefficient (see Methods). See Methods for how IRF, rapid adjustment and ERF are calculated as a combination of direct 
model output, double radiation calls and application of radiative kernels, following Myhre et

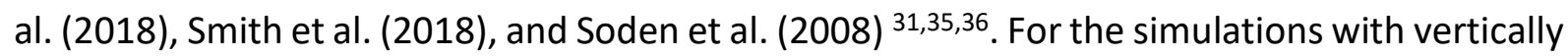
constrained profile $(\mathrm{VC})$ the surface temperature change is $0.03( \pm 0.02) K$, compared to 0.07 $( \pm 0.03) \mathrm{K}$ in STD. The results are given with one standard deviation from the four models, which give the same relative standard deviation as using the 10 PDRMIP models performing the BC experiment (see Table S2). The IRF is much stronger in STD than VC due to a higher BC total abundance in the upper troposphere where its absorption is particularly efficient ${ }^{37-39}$. However, the rapid adjustments are also stronger in STD, producing a compensating effect that makes the ERF and temperature response the in two experiments more comparable. All rapid adjustment terms are stronger in STD than in VC, with the strongest difference originating from cloud responses. The negative rapid adjustment involves changes in (land) surface, tropospheric and stratospheric temperatures caused by the atmospheric heating by $\mathrm{BC}$, which increases the longwave radiation to space (Planck feedback). See further discussion in Smith, et al. ${ }^{31}$ on the impact on longwave radiation and how this differs among climate drivers. Water vapor change is a positive rapid adjustment resulting from increased atmospheric temperatures. Earlier studies have focused strongly on BC rapid adjustment due to clouds ${ }^{7}$, but our results illustrate the importance of including all rapid adjustment terms. In the STD experiment the rapid adjustment due to clouds is similar in magnitude to the sum of the other rapid adjustment terms. For the VC experiment the rapid adjustment of clouds is $40 \%$ of the total rapid adjustment in a multi-model mean. However, the cloud rapid adjustment has a strong inter-model standard deviation, and is even positive in one of the models. The ERF is $0.17( \pm 0.08)$ [0.16 to 0.32 ] W $\mathrm{m}^{-2}$ and $0.08( \pm 0.05) \mathrm{W} \mathrm{m}^{-2}$ for BC STD and BC VC, respectively. For BC STD the rapid adjustment contributes to an ERF that is $50 \%$ smaller than the IRF of $0.34 \mathrm{~W} \mathrm{~m}^{-2}$. For $\mathrm{VC}$ the rapid adjustment causes a $43 \%$ reduction from an IRF of $0.14 \mathrm{~W} \mathrm{~m}^{-2}$. In addition to the atmospheric rapid adjustment terms, the prescribed seasurface temperature simulations used to quantify ERF show small land surface temperature and albedo changes.

Geographical distributions of the multi-model mean surface temperature change are shown in Figure 2, displaying a strongly inhomogeneous pattern. The warming is much stronger over continents than over oceans. However, many of the regions that have a high abundance of BC, such as Southeast Asia, show a very modest warming or even cooling. The geographical pattern of warming is similar in STD and VC. The temperature change from the fully coupled climate model simulations is taken as a mean over the years 50-100 and will likely overstate the current temperature change due to present-day anthropogenic $\mathrm{BC}$, since the model has had many decades to respond to the current levels, including a component from the deep ocean, unlike the real world. Therefore, we consider this an upper-bound from the 4 models. A lower bound found by using a 5-year mean around year 20 is about $20 \%$ weaker than our upper-bound (see supplementary text for further discussion).

In Figure 3, we decompose IRF, rapid adjustment and ERF into shortwave (SW) and longwave (LW) radiation components. The SW and LW ERF are direct output from the model simulations, 
whereas IRF and rapid adjustment terms are derived using the same approach as in Figure 1 (see Methods). The IRF is almost solely a result of BC interacting with SW radiation. Note, however, that two of the four models have a very weak LW IRF effect in the simulations. The total rapid adjustment mainly affects the LW radiation. Looking into the radiative distribution of the individual rapid adjustment terms (not shown), the temperature rapid adjustment terms impact LW radiation only, and water vapor and clouds also mostly impact the LW radiation. LW rapid adjustment from clouds and water vapor are up to half of the total LW rapid adjustment in magnitude but their rapid adjustment terms are of opposite sign. Similarly, SW rapid adjustments for clouds are negative and those for water vapor are positive. Because of these compensating terms, the total SW rapid adjustment varies in sign across the models. The net radiation changes behind the rapid adjustment in Figure 1 are very different for the two experiments, and it can be seen in Fig. 3 that this originates from differences in LW radiation. Supplementary Figure S1 shows the residuals in the rapid adjustment calculations. Residuals can be derived due to the availability of double-radiation calls and because BC induced changes in LW radiation are almost entirely due to rapid adjustments. The residuals are particularly small for net $(\mathrm{LW}+\mathrm{SW})$ rapid adjustment. As uncertainties in the kernel simulations of temperature and water vapor changes are relatively small ${ }^{31}$, this further indicates that residuals in the cloud rapid adjustment calculations are small.

Atmospheric vertical profiles of change in temperature, cloud fraction, relative humidity and specific humidity are shown in Figure 4 for the two experiments. The profiles from the BC STD and $B C$ VC simulations are very different in the upper troposphere for all models, where the BC STD simulation shows strong changes while BC VC has almost none. In the lower troposphere, temperature changes and clouds changes are relatively similar for the two simulations. The cloud fraction changes follow largely the relative humidity profile. Figure 1 shows a particularly large change in the cloud rapid adjustment between the BC STD and BC VC experiments, indicating that cloud changes in the middle and upper troposphere are especially important. Specific humidity changes are positive throughout the troposphere with much stronger increases in BC STD than in BC VC. The model diversity (shown as one standard deviation) is larger for BC STD than BC VC but varies vertically. The model diversity is generally low for cloud changes. Results for the individual models are shown in Supplementary Figure S2. No particular model is dominating the model spread, except for temperature changes around $100 \mathrm{hPa}$ in BC STD where NCAR-CESM1-CAM4 has a much larger temperature increase than the three other models.

In this study we have shown ERF due to BC over the industrial era to be lower than IRF (the direct $\mathrm{BC}$ aerosol effect) by around $50 \%$ in the multi-model mean. ERF has previously been found to be the most representative way to compare the surface temperature change from a perturbation to the Earth's energy budget for different climate drivers, including $B{ }^{29}$. The total rapid adjustment due to $\mathrm{BC}$ is strongly negative, and recent findings ${ }^{31}$ underline the importance of atmospheric temperature increase and negative cloud rapid adjustment. Here we have found that values of IRF, rapid adjustment and ERF are consistent among four climate 
models, as are the underlying physical processes of vertical changes in atmospheric temperature, water vapor, and clouds. This consistency includes simulations from three climate models using concentration fields of $B C$ and one model used emissions to derive the BC atmospheric concentration. Uncertainties in the climate effect of BC are particularly associated to emissions, atmospheric residence time and optical properties ${ }^{2,8,40}$. These include emission height, particle size, and internal versus external mixing. Regarding particle size and mixing properties the uncertainty is at emission and through processes in the atmosphere. The version 2016 BC emissions from Community Emission Data Set (CEDS) ${ }^{22}$ are $66 \%$ higher than used in previous multi-model studies or assessments, partly because of higher emissions in 2000 and partly as a result of increase in BC emission since 2000 . However, the most recent version of the CEDS data (version 2021) are only 17\% higher than emissions from previous multi-model studies. This is mainly caused by a revisiting of emission before 2014 and a continued reduction after 2014. Results for versions 2021 and 2016 are shown in Table S3. BC emission data have been assessed earlier to a factor of two uncertainty ${ }^{41}$. The abundance of $\mathrm{BC}$ in the upper troposphere is too large compared to observations in the previous generation of global aerosol models ${ }^{24,25}$. In this study, results are shown both for models representative of the previous generation of models, and models which provide much better agreement with observations in the upper troposphere. The magnitude of the mass absorption coefficient is crucial for the $\mathrm{BC}$ radiative effect ${ }^{8}$ and has been measured in average to be around $7.5 \pm 1.2 \mathrm{~m}^{2} \mathrm{~g}^{-1}$ (at $550 \mathrm{~nm}$ ) for freshly generated particles ${ }^{2}$. The enhancement of the mass absorption coefficient when $B C$ is coated by non-BC aerosols is uncertain, but several observations indicate an overall mass absorption coefficient of around $10 \mathrm{~m}^{2} \mathrm{~g}^{-1}$ (at $550 \mathrm{~nm})^{20}$. See supplementary Table S1, which shows a large range in observed mass absorption coefficient values, likely due to regional differences and different measurements techniques ${ }^{20}$. The mean $\mathrm{BC}$ mass absorption coefficient in the four climate models in this study is $7.3 \mathrm{~m}^{2} \mathrm{~g}^{-1} \pm 10 \%$ (550nm). Although these numbers are based on column integrated absorption optical depths in the models, unlike the observationally based values, they are most likely on the lower side compared to observations (see Supplementary Table 1), which is the reason behind the scaling applied for the absorption properties here.

$\mathrm{BC}$ has been suggested as an efficient target for climate change mitigation ${ }^{42,43}$ and is therefore of relevance for policy discussions. In such discussions, simplified metrics are generally used to quantify the contributions to climate change of emissions of different climate drivers. Global Warming Potential (GWP), which quantifies the radiative forcing over time relative to that from $\mathrm{CO}_{2}$ emissions, is the most applied metric, embedded in the United Nations Framework Convention on Climate Change (UNFCCC). GWP values however depend on the chosen time horizon ${ }^{44}$, with the most common choice being 100 years. Here we find that the $\mathrm{GWP}_{100}$ changes from a value of 680 using IRF (direct aerosol effect) from previous generation climate models, to 160 ( \pm 120 ) for ERF for BC constrained (through its vertical profile) by observations. The uncertainty is estimated from uncertainty in ERF and emissions. A low GWP value is consistent with a low surface temperature change from anthropogenic induced $B C$ in fully coupled climate simulations. In addition, anthropogenic emissions of BC are co-emitted 
with scattering aerosols having a strong cooling. Applying ERF instead of IRF in GWP calculations is particularly important for $\mathrm{BC}$, which imply a reduced GWP value compared to earlier scientific publications.

\section{Methods Concepts}

IRF - Instantaneous Radiative Forcing: The immediate energy imbalance at the top-ofatmosphere (TOA) caused by direct interactions between changed atmospheric BC burden and radiation, positive for increased energy input to the earth system.

RA - Rapid Adjustments: short-term adjustments of atmospheric properties to the IRF, which do not influence the ground surface temperature.

ERF - Effective Radiative Forcing: The TOA radiative energy perturbation due to the combination of IRF and the Rapid Adjustments and thus the TOA perturbation after RA have taken place, positive for increased energy input to the earth system.

Climate Response: Any changes in climate variables in response to ERF, including the deep oceans. Ideally, a full climate response to an imposed ERF is the difference between climate states in long-term equilibrium with and without the imposed ERF. The high inertia of the deep oceans hampers such estimates in practice. Instead, a Transient Climate Response is estimated after a given time for partial adjustment; in this case we use 100 years long coupled simulations.

Models: This study uses a subset of 4 PDRMIP models out of 10 Precipitation Driver Response Model Intercomparison Project (PDRMIP) models ${ }^{45}$. We use simulations from the four global climate models ECHAM-HAM-M7, GISS, NCAR-CESM-CAM4 and NorESM1. In PDRMIP, atmosphere-land simulations with prescribed sea surface temperatures (AMIP-type) and fully atmosphere-land-ocean coupled (CMIP-type) simulations are applied for a large set of climate drivers, and a reference simulation representing current climate conditions. For a further description of the PDRMIP models see Myhre, et al. ${ }^{45}$.

Simulations: The BC climate driver is scaled to its atmospheric change during the industrial era. Prescribed concentration fields are imported in three of the models (GISS, NCAR-CESMCAM4 and NorESM1) which thus are run concentration-driven without feedback between climate variables and BC-concentrations. The fourth model (ECHAM) calculates BCconcentrations from emissions, and thus allows feedbacks between $\mathrm{BC}$ and atmospheric variables. Both 15 yearlong AMIP-type and 100 year long CMIP-type simulations are performed.

Each model produces a standard set of climate response experiments (BC STD) based on importing $B C$-data from the $B C \times 10$ (BC-concentrations/emissions multiplied with 10) core set of PDRMIP simulations. Imported concentration fields in BC STD are multi-model mean fields from AeroCom ${ }^{40}$. A new set of simulations (BC VC) are performed by importing (in GISS, NCAR- 
CESM-CAM4 and NorESM1) or producing (in ECHAM) lifetime-adjusted BCx10-data to constrain the concentration profile to observations. We use a single model field for imported BC-concentrations in the $B C$ VC experiment ${ }^{37}$. The $B C$ over abundance in the upper troposphere is reduced by increasing the wet removal of $B C$, which results in a shorter lifetime. Various sensitivity simulations are performed in Hodnebrog, et al. ${ }^{37}$ to achieve a realistic agreement to the aircraft measurements. The lifetime of BC in the BC VC for the models GISS, NCAR-CESM-CAM4 and NorESM1 is 3.9 days ${ }^{37}$ compared to 7.4 days in BC STD ${ }^{15}$. In the emission-driven simulations in ECHAM-HAM the wet removal tendencies of $B C$ are scaled by a factor of 2 resulting in a change in the lifetime from 7.4 days (in BC STD) to 3.7 days (in BC $\mathrm{VC})$.

In the BC STD PDRMIP experiment the four selected models have a mean ERF within $1 \%$ of the mean of the 10 PDRMIP models, whereas the number is $25 \%$ for surface air temperature change.

Constraining to observed mass absorption coefficient and emission data: All results are scaled to best match current $\mathrm{BC}$ emission estimates using Community Emission Data set (CEDS) version $2021^{23}$. The previously published BC emission in CEDS (version 2016) is 66\% larger (from 4.6 to $7.6 \mathrm{Tg} \mathrm{yr}^{-1}$ ) than the emissions used in AeroCom data set (BC STD experiment) due to strong increase in recent years and overall improved estimation of $B C$ sources ${ }^{22}$. However, the most recent version of the CEDS data (version 2021) has only a $17 \%$ (from 4.6 to $5.4 \mathrm{Tg} \mathrm{yr}^{-}$ $\left.{ }^{1}\right)$ higher emissions than used in previous multi-model studies. This is mainly caused by a revisiting of emission before 2014 and a continued reduction after 2014. In all Figures and numbers, the most recent CEDS data are used. In the Supplementary Table S3, we report results from $B C$ emissions of 5.4 and $7.6 \mathrm{Tg} \mathrm{yr}^{-1}$. The concentration field applied in the BC VC experiment is derived from the EU-project ECLIPSE emission data set ${ }^{46,47}$, with a total BC emission of $7.1 \mathrm{Tg} \mathrm{yr}^{-1}$ (5.5 and $1.6 \mathrm{Tg} \mathrm{yr}^{-1}$, respectively from anthropogenic and natural sources)

Observations of mass absorption coefficients vary strongly ${ }^{2,20}$, see Supplementary Table 1. Models have typically lower mass absorption coefficient values than observations. The mean mass absorption coefficient among the four models applied in this study is $7.3 \mathrm{~m}^{2} \mathrm{~g}^{-1} \pm 10 \%$ $(550 \mathrm{~nm})$. We scale this value to $10 \mathrm{~m}^{2} \mathrm{~g}^{-1}(550 \mathrm{~nm})$, which we find as a representative value from the selected values in Supplementary Table 1.

The scaling of the results by emissions and mass absorption coefficient are done on all postprocessed GCM output. All results in this study thus represent a change in BC from preindustrial to present by emissions of $5.4 \mathrm{Tg} \mathrm{yr}^{-1}$ and mass absorption coefficient of $10 \mathrm{~m}^{2} \mathrm{~g}^{-1}$ (550nm). For the BC STD simulation this corresponds to a scaling by $1.6 / 10$ of the original results ( 10 due to the setup of $10 x B C, 1.37$ for mass absorption coefficient and 1.17 for the emissions). The scaling is applied to the multi-model mean numbers.

Calculations of ERF and rapid adjustments: ERF and surface temperature changes are directly derived output from the PDRMIP models, respectively from fixed sea surface temperature 
simulations (AMIP-type) and fully coupled simulations (CMIP-type). Results from fixed sea surface temperature simulations are taken as mean of years 6-15 and results from coupled simulations as mean of year 51-100 ${ }^{34}$. Radiative kernel simulations ${ }^{36}$ are applied for quantifications of the individual rapid adjustments terms using a mean of 5 different radiative kernels ${ }^{31,35}$. Three of the models have implemented double radiation calls for quantification of IRF, whereas for NorESM1 IRF is taken as the difference between ERF and rapid adjustment. When IRF is directly quantified, the residuals in the kernel simulations are discussed in the text. Similarly, BC IRF almost exclusively influences the SW radiation; therefore, the residual can be derived from LW ERF and kernel calculations.

GWP calculations: Following the definition of Global Warming Potential (GWP) ${ }^{48}$ it is obtained by time integration of forcing due to $1 \mathrm{~kg}$ pulse emission of $B C$ (absolute GWP - AGWP) divided by $A G W P$ for $\mathrm{CO}_{2}$. AGWP for $\mathrm{BC}$ can be calculated as the forcing divided by the emissions, due to the short lifetime of $B C$ forcing mechanisms ${ }^{2}$. We use the $A G W P$ for $\mathrm{CO}_{2}$ value from IPCC AR5 ${ }^{44}$, which is $9.1710^{-14} \mathrm{~W} \mathrm{~m}^{-2} \mathrm{yr}\left(\mathrm{kg} \mathrm{CO}_{2}\right)^{-1}$ for a 100 -year time horizon.

\section{Acknowledgement:}

GM was supported by the European Union's Horizon 2020 Research and Innovation programme (CONSTRAIN project, grant agreement no. 820829). DWP and PS acknowledge funding from the UK NERC CLARIFY project NE/L013479/1. PS additionally acknowledges support from the European Research Council (ERC) project RECAP under the European Union's Horizon 2020 research and innovation program with grant agreement 724602 and the European Union's Horizon 2020 research and innovation programme FORCeS under grant agreement No 82120. CJS was supported by a NERC/IIASA Collaborative Research Fellowship (NE/T009381/1). TA was supported by the Met Office Hadley Centre Climate Programme funded by BEIS and Defra. 
a)

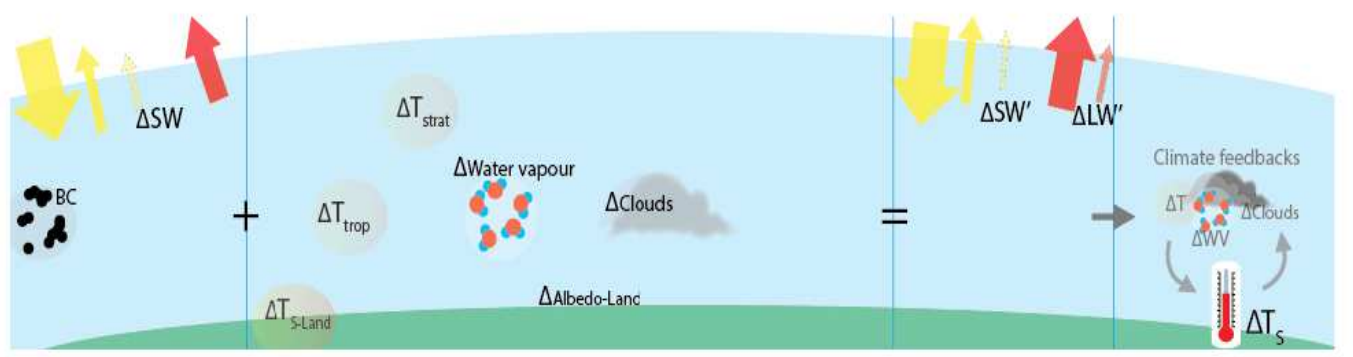

b)

PDRMIP scaled to current BC emissions (CEDS) $\quad$ BC standard (BC STD) $\quad$ BC vertical constrain (BCVO)

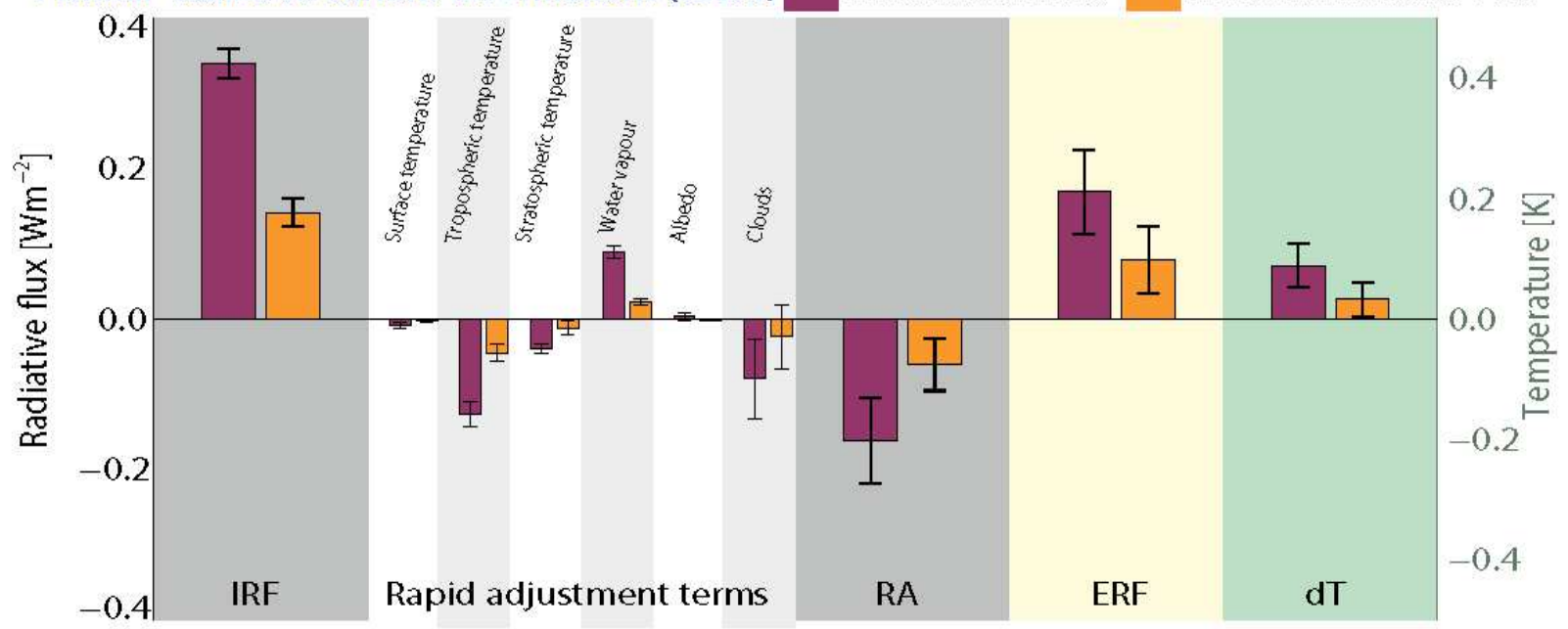

Figure 1: (a) Schematic illustration of the instantaneous change in top of the atmosphere radiative fluxes, rapid adjustments, and feedback processes. Yellow arrows are for shortwave radiation and red for longwave radiation. The thinnest lines (one for shortwave and one for longwave) are perturbations to the radiation budget by BC. (b) Calculated global mean values from the two experiments BC STD and BC VC, showing instantaneous radiative forcing (IRF), rapid adjustments (RA), effective radiative forcing (ERF) and surface temperature change. Uncertainty ranges are taken as one standard deviation among the four climate models. 
Surface temperature change $\left[{ }^{\circ} \mathrm{C}\right]$

354

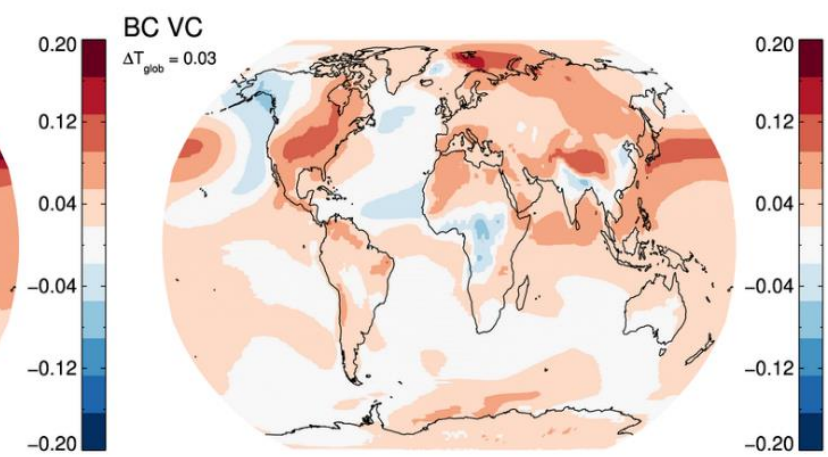

Figure 2: Multi-model annual mean surface temperature change for the BC STD and BC VC experiments.

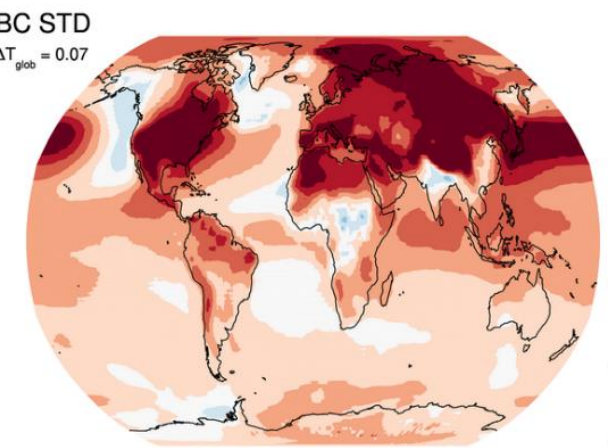

(1)

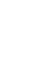

PDRMIP scaled to current BC emissions (CEDS)

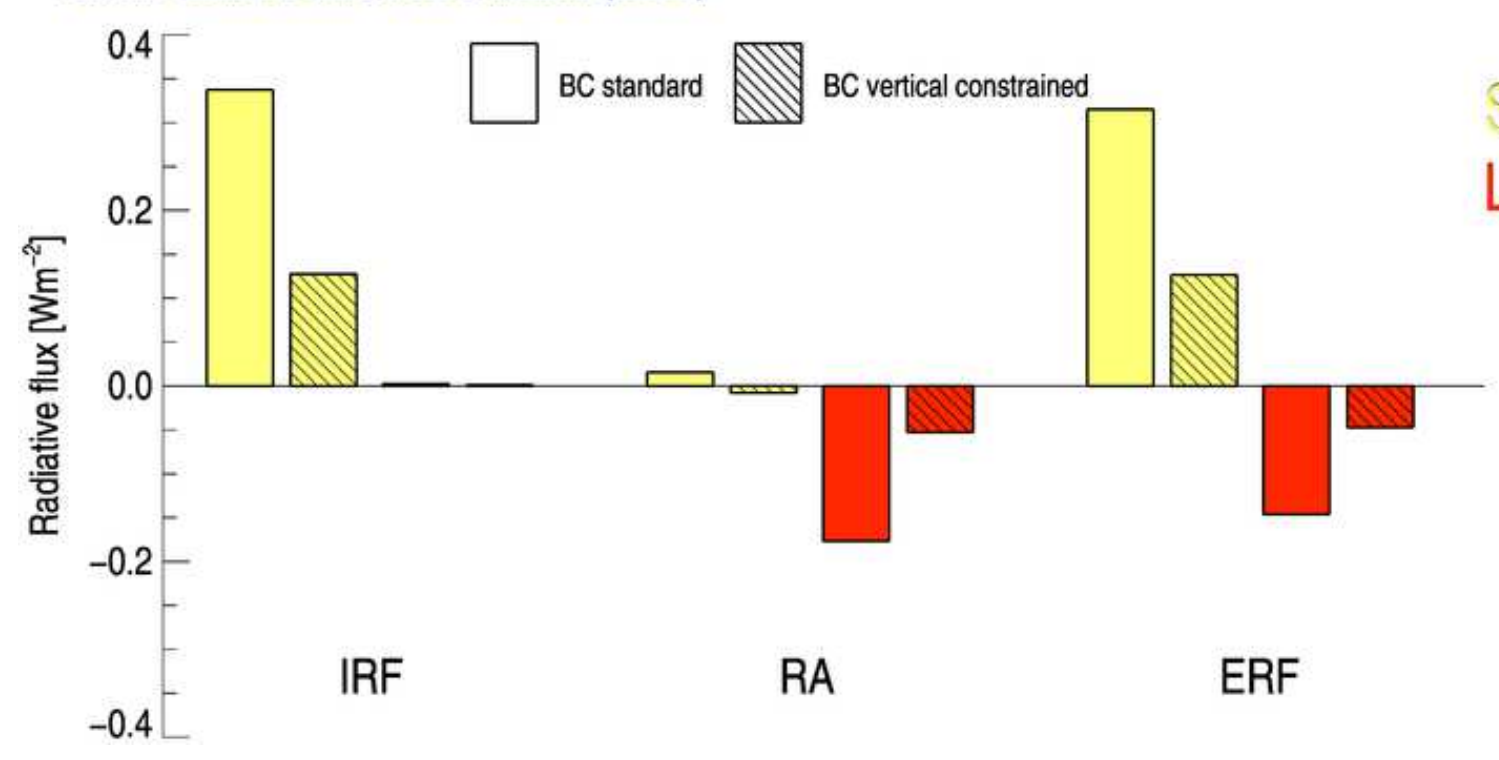

Figure 3: Global mean instantaneous radiative forcing (IRF), rapid adjustments (RA), effective radiative forcing (ERF) divided into longwave (LW) and shortwave (SW) radiation from the two experiments STD (full bars) and BC VC (bars with lines). Net values (SW + LW) are shown in Figure 1. 

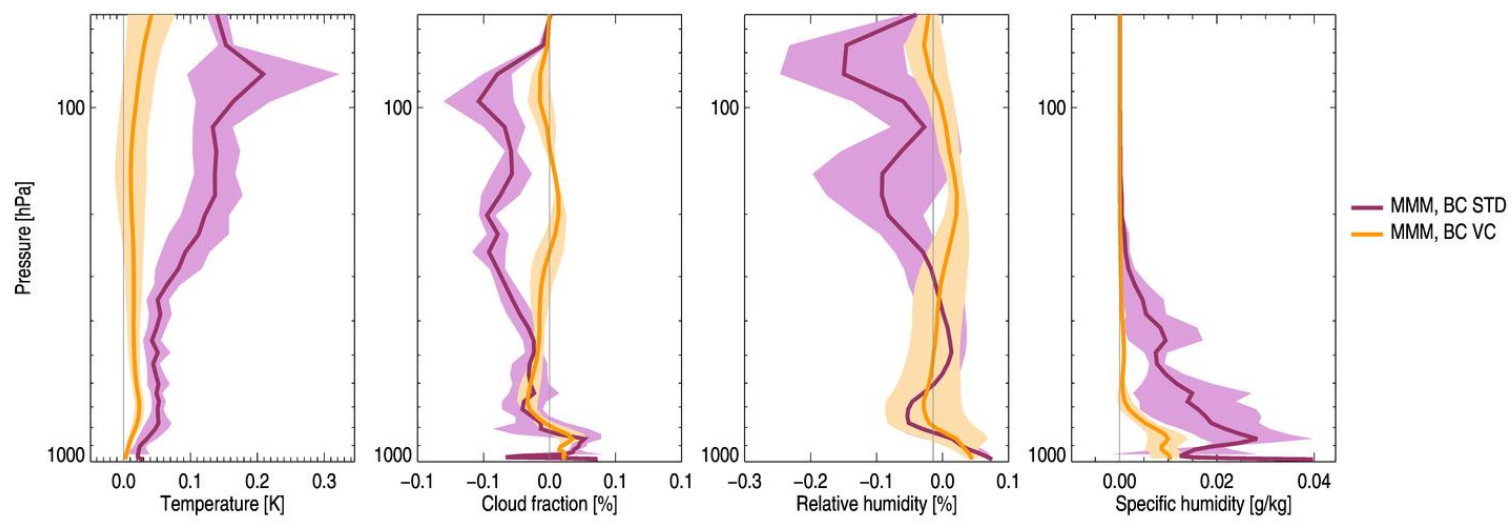

368 Figure 4: Atmospheric vertical profiles of changes in temperature, cloud fraction, relative humidity, and specific humidity for the two experiments BC STD and BC VC. 
Haywood, J. M. and Shine, K. P., The effect of anthropogenic sulfate and soot aerosol on the clear-sky planetary radiation budget. Geophys. Res. Lett. 22, 603-606 (1995). Bond, T. C. et al., Bounding the role of black carbon in the climate system: A scientific assessment. J. Geophys. Res.-Atmos. 118, 5380-5552 (2013).

Chylek, P. and Wong, J., Effect of absorbing aerosols on global radiation budget. Geophys. Res. Lett. 22, 929-931 (1995).

Stier, P. et al., Host model uncertainties in aerosol radiative forcing estimates: results from the AeroCom Prescribed intercomparison study. Atmos. Chem. Phys. 13, 3245-3270 (2013). Ackerman, A. S. et al., Reduction of tropical cloudiness by soot. Science 288, 1042-1047 (2000).

Hansen, J., Sato, M., and Ruedy, R., Radiative forcing and climate response. J. Geophys. Res.Atmos. 102, 6831-6864 (1997).

Koch, D. and Del Genio, A. D., Black carbon semi-direct effects on cloud cover: review and synthesis. Atmos. Chem. Phys. 10, 7685-7696 (2010).

Boucher, O. et al., Clouds and Aerosols, in Climate Change 2013: The Physical Science Basis. Contribution of Working Group I to the Fifth Assessment Report of the Intergovernmental Panel on Climate Change, edited by T. F. Stocker et al. (Cambridge University Press, Cambridge, United Kingdom and New York, NY, USA, 2013), pp. 571-657.

Johnson, B. T., Shine, K. P., and Forster, P. M., The semi-direct aerosol effect: Impact of absorbing aerosols on marine stratocumulus. Q. J. R. Meteorol. Soc. 130, 1407-1422 (2004). Zhou, X. et al., Impacts of solar-absorbing aerosol layers on the transition of stratocumulus to trade cumulus clouds. Atmos. Chem. Phys. 17, 12725-12742 (2017).

Herbert, R. J., Bellouin, N., Highwood, E. J., and Hill, A. A., Diurnal cycle of the semi-direct effect over marine stratocumulus in large-eddy simulations. Atmos. Chem. Phys. Discuss. 2019, 1-38 (2019).

Gordon, $\mathrm{H}$. et al., Large simulated radiative effects of smoke in the south-east Atlantic. Atmos. Chem. Phys. 18, 15261-15289 (2018).

Brioude, J. et al., Effect of biomass burning on marine stratocumulus clouds off the California coast. Atmos. Chem. Phys. 9, 8841-8856 (2009).

Koren, I., Martins, J. V., Remer, L. A., and Afargan, H., Smoke invigoration versus inhibition of clouds over the Amazon. Science 321, 946-949 (2008).

Stjern, C. W. et al., Rapid Adjustments Cause Weak Surface Temperature Response to Increased Black Carbon Concentrations. J. Geophys. Res. - Atmos. 122, 11462-11481 (2017).

Baker, L. H. et al., Climate responses to anthropogenic emissions of short-lived climate pollutants. Atmos. Chem. Phys. 15, 8201-8216 (2015).

Penner, J. E., Zhang, S. Y., and Chuang, C. C., Soot and smoke aerosol may not warm climate. J. Geophys. Res.-Atmos. 108, 4657 (2003).

Bellouin, N. et al., Bounding Global Aerosol Radiative Forcing of Climate Change. Rev. Geophys. 58, e2019RG000660 (2020).

Andrews, E., Ogren, J. A., Kinne, S., and Samset, B., Comparison of AOD, AAOD and column single scattering albedo from AERONET retrievals and in situ profiling measurements. Atmos. Chem. Phys. 17, 6041-6072 (2017). Zanatta, M. et al., A European aerosol phenomenology-5: Climatology of black carbon optical properties at 9 regional background sites across Europe. Atmos. Environ. 145, 346-364 (2016).

Wang, R. et al., Trend in Global Black Carbon Emissions from 1960 to 2007. Environmental Science \& Technology 48, 6780-6787 (2014).

Hoesly, R. M. et al., Historical (1750-2014) anthropogenic emissions of reactive gases and aerosols from the Community Emissions Data System (CEDS). Geosci. Model Dev. 11, 369-408 (2018). 
O'Rourke, P. R. et al., (Zenodo. http://doi.org/10.5281/zenodo.4509372., 2021).

Samset, B. H. et al., Modelled black carbon radiative forcing and atmospheric lifetime in AeroCom Phase II constrained by aircraft observations. Atmos. Chem. Phys. 14, 12465-12477 (2014).

25 Schwarz, J. P. et al., Global-scale black carbon profiles observed in the remote atmosphere and compared to models. Geophys. Res. Lett. 37, L18812, doi:18810.11029/12010gl044372 (2010). Lund, M. T. et al., Short Black Carbon lifetime inferred from a global set of aircraft observations. npj Climate and Atmospheric Science 1 (2018). Wang, R. et al., Spatial Representativeness Error in the Ground-Level Observation Networks for Black Carbon Radiation Absorption. Geophys. Res. Lett. 45, 2106-2114 (2018). Boucher, $\mathrm{O}$. et al., Jury is still out on the radiative forcing by black carbon. Proceedings of the National Academy of Sciences 113, E5092-E5093 (2016).

Richardson, T. B. et al., Efficacy of Climate Forcings in PDRMIP Models. J. Geophys. Res. Atmos. 124, 12824-12844 (2019).

Sherwood, S. C. et al., Adjustments in the Forcing-Feedback Framework for Understanding Climate Change. Bull. Am. Meteorol. Soc. 96, 217-228 (2015).

Smith, C. J. et al., Understanding Rapid Adjustments to Diverse Forcing Agents. Geophys. Res. Lett. 45, 12,023-012,031 (2018).

Johnson, B. T., Haywood, J. M., and Hawcroft, M. K., Are Changes in Atmospheric Circulation Important for Black Carbon Aerosol Impacts on Clouds, Precipitation, and Radiation? J. Geophys. Res. - Atmos. 124, 7930-7950 (2019).

Suzuki, K. and Takemura, T., Perturbations to Global Energy Budget Due to Absorbing and Scattering Aerosols. J. Geophys. Res. - Atmos. 124, 2194-2209 (2019).

Samset, B. H. et al., Fast and slow precipitation responses to individual climate forcers: A PDRMIP multimodel study. Geophys. Res. Lett. 43, 2782-2791 (2016).

Myhre, G. et al., Quantifying the Importance of Rapid Adjustments for Global Precipitation Changes. Geophys. Res. Lett. 45, 11,399-311,405 (2018).

Soden, B. J. et al., Quantifying Climate Feedbacks Using Radiative Kernels. J. Climate 21, 3504-3520 (2008).

Hodnebrog, $\varnothing$., Myhre, G., and Samset, B. H., How shorter black carbon lifetime alters its climate effect. Nat Commun 5, 5065 (2014).

Samset, B. H. et al., Black carbon vertical profiles strongly affect its radiative forcing uncertainty. Atmos. Chem. Phys. 13, 2423-2434 (2013). its global direct radiative forcing? Geophys. Res. Lett. 37, L20807, doi:20810.21029/22010gl044555 (2010).

40 Myhre, G. et al., Radiative forcing of the direct aerosol effect from AeroCom Phase II simulations. Atmos. Chem. Phys. 13, 1853-1877 (2013).

1 Bond, T. C. et al., A technology-based global inventory of black and organic carbon emissions from combustion. J. Geophys. Res.-Atmos. 109, D14203 (2004).

Hansen, J. et al., Global warming in the twenty-first century: An alternative scenario. Proc. Natl. Acad. Sci. U.S.A. 97, 9875-9880 (2000).

Jacobson, M. Z., Control of fossil-fuel particulate black carbon and organic matter, possibly the most effective method of slowing global warming. J. Geophys. Res.-Atmos. 107 (2002). Myhre, G. et al., Anthropogenic and Natural Radiative Forcing, in Climate Change 2013: The Physical Science Basis. Contribution of Working Group I to the Fifth Assessment Report of the Intergovernmental Panel on Climate Change, edited by T. F. Stocker et al. (Cambridge University Press, Cambridge, United Kingdom and New York, NY, USA, 2013), pp. 659-740. Myhre, G. et al., PDRMIP: A Precipitation Driver and Response Model Intercomparison Project-Protocol and Preliminary Results. Bull. Am. Meteorol. Soc. 98, 1185-1198 (2017). 
$472 \quad 46$
Klimont, Z. et al., Global anthropogenic emissions of particulate matter including black carbon. Atmos. Chem. Phys. 17, 8681-8723 (2017).

Stohl, A. et al., Evaluating the climate and air quality impacts of short-lived pollutants. Atmos. Chem. Phys. 15, 10529-10566 (2015).

Shine, K. P., Derwent, R. G., Wuebbles, D. J., and Morcrette., J.-J., Radiative Forcing of Climate. , edited by J. T. Houghton, G. J. Jenkins, and J. J. Ephraums (Cambridge University Press., Cambridge, Great Britain, New York, NY, 7530 USA and Melbourne, Australia, 1990. 


\section{Supplementary Files}

This is a list of supplementary files associated with this preprint. Click to download.

- Supplementarysubmitted.pdf 